\title{
Faktor Terpenting dalam Membangun Unique Selling Proposition untuk Menjangkau Konsumen Kelas Menengah Indonesia
}

\author{
Christian Anggrianto ${ }^{1}$, Nassiriah Shaari ${ }^{2}$, Norsiah binti Abdul Hamid ${ }^{3}$ \\ ${ }^{1}$ Jurusan Visual Communication Design, Universitas Ciputra, Surabaya, Indonesia \\ 2,3 Universitas Utara Malaysia \\ E-mail: Christ.ang@ciputra.ac.id
}

\begin{abstract}
Abstrak
Indonesia mampu mencatat angka pertumbuhan ekonomi yang relatif tinggi dan konsisten meski dunia dilanda krisis keuangan global serta memiliki peningkatan angka konsumsi domestik yang kuat. Pertumbuhan kelas menengahnya membuat Indonesia menjadi salah satu negara berkembang yang menarik perhatian para Investor dan pebisnis, hal tersebut secara tidak langsung menimbulkan persaingan yang makin tajam untuk merebut pasar kelas menengah Indonesia. Oleh karena itu, penelitian ini bertujuan untuk mengetahui faktor terpenting dalam membangun unique selling proposition untuk menjangkau konsumen kelas menengah indonesia. Landasan teori penelitian ini adalah teori Unique selling proposition, postioning, branding, dan kelas menengah Indonesia. Metode penelitian yang akan digunakan adalah metode penelitian triangulasi, yang sering digunakan dalam penelitian sains sosial yang mengacu pada aplikasi dan kombinasi beberapa metode penelitian dalam studi fenomena yang sama, dan melakukan wawancara pada narasumber yang berpengalaman dalam bidang.
\end{abstract}

Kata kunci: Unique Selling Proposition, Desain, Branding, Kelas Menengah Indonesia.

\begin{abstract}
Despite of the world global crisis, Indonesia are able to record high and consistent economic growth, it also gain a strong and increasing domestic consumption number. The growing number of Indonesian middleclass that attract investors and businessmen, but the attraction has indirectly cause a vicious competition between businesses to seize the middle-class market. Therefore, this research aims to identified the most important factor in building a unique selling preposition to reach out to the middle-class consumer in Indonesia. The basic theory that used in this research are Unique selling proposition, positioning, branding, and the middle class market. The research method that will be used is triangulation research method, a method that often use in social science research, it refer to the application and combination of several methods focusing on the same phenomenon.
\end{abstract}

Keywords: Unique Selling Proposition, Design, Branding, Indonesian middle class.

\section{Pendahuluan}

Indonesia mampu mencatat angka pertumbuhan ekonomi yang konsisten relatif tinggi sejak dunia dilanda krisis keuangan global dan mempunyai peningkatan konsumsi domestik yang kuat. Indonesia yang sedang tumbuh kelas menengahnya menjadi salah satu negara berkembang yang menjadi perhatian para investor. Menurut data Badan Pendidikan dan Pelatihan Keuangan Kementerian Keuangan Pertumbuhan kelas menengah sebesar 64\% (di tahun 2012 berjumlah 41,6 juta jiwa dan 2020 berjumlah 68,2 juta jiwa).

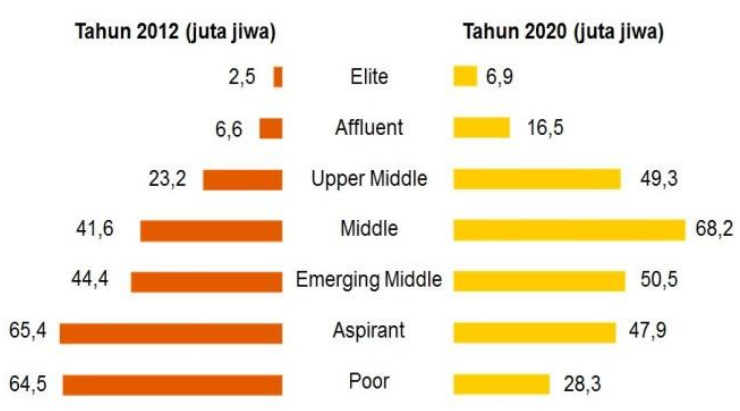

http://www.bppk.kemenkeu.go.id/publikasi/artikel/ 167-artikel-pajak/21014-penghasilan-kelas-menengah-naik-potensi-pajak 
Kelas menengah adalah istilah kelas sosial ekonomi antara kelas pekerja dan kelas atas. Biasanya di dalam kelas menengah termasuk para profesional, pekerja terampil, serta manajemen bawah dan menengah. Pertumbuhan kelas menengah melambangkan kemakmuran dan pertumbuhan ekonomi, Foster dan Wolfson (1922) dari Oxford University menyatakan bahwa menjadi begara industri yang maju salah satu faktor penting adalah keberadaan kelas menengah. Kelas menengah bisa memberikan sumbangan supply tenaga kerja dan merupakan key market demand bagi produk industri nasional.

Kisaran pendapatan kelas menengah bervariasi dari satu ke tempat lain, oleh karena itu faktor yang menentukan rentang pendapatan dari tempat tertentu harus dipertimbangkan. Menurut Banarjee dan duflo (2008) mendefinisikan kelas menengah sebagai individu yang mempunyai pengeluaran sekitar $\$ 2$ sampai $\$ 20$ atau dalam kurs rupiah dengan asumsi $\$ 1$ sama dengan $\mathrm{Rp}$. 13.500 menjadi Rp. 27.000 sampai Rp. 270.000 per hari. Kelas menengah juga disebut sebagai consumer class karena dianggap mempunyai kemampuan untuk berbelanja secara lebih, mampu membeli barang bermerk dan memenuhi keinginan-keinginannya seperti barang eletronik, fashion, gadget canggih, makanan dan gaya hidup yang modern.

Menurut Boston Consulting Group (BCG) pada tahun 2020 akan ada sekitar 141 juta populasi kelas menengah di Indonesia. Jumlah tersebut melebihi total populasi negara-negara di ASEAN lain, termasuk Malaysia, Thailand dan Filipina. Jumlah populasi kelas menengah yang melaju cepat didukung kondisi ekonomi yang terus bertumbuh mendorong sejumlah investor asing membangun basis produksi di Indonesia.

Pertumbuhan ekonomi Indonesia yang mendorong konsumsi dan belanja kelas menengah yang semakin meningkat. Hal ini merupakan peluang bagi wirausaha Indonesia, mereka dapat memasarkan dan menjual produknya untuk memenuhi kebutuhan belanja kelas menengah Indonesia. Memasuki era Masyarakat Ekonomi ASEAN (MEA) di tahun 2015 merupakan tantangan sekaligus peluang buat Indonesia. Para wirausaha Indonesia bisa memanfaatkan konsumen kelas menengah Indonesia, sehingga negaranegara tetangga di ASEAN tidak bisa menggunakannya. Peluang ini akan mendorong wirausaha untuk memanfaatan potensi consumer class dan meningkatkan potensi bisnis mereka.

Jika dilihat dari kemampuan membayarnya keberadaan kelas menengah merupakan kategori kelompok konsumen yang sangat strategis. Kelas menengah dengan tingkat penghasilan yang ting- gi, pada umumnya mengalami pergeseran konsumsi. Dari konsumsi atas pemenuhan "kebutuhan" menjadi konsumsi untuk pemenuhan "keinginan". Adanya pergeseran nilai dari yang semula untuk fase bertahan hidup menjadi fase untuk mengaktualisasikan diri, mengikuti tren atau memenuhi kebutuhan bersosialisasi dalam hal konsumsinya.

Dengan meningkatnya pertumbuhan ekonomi di Indonesia serta untuk memenuhi kebutuhan belanja kelas menengah merupakan peluang bisnis bagi para pengusaha di Indonesia. Oleh karena itu peneliti tertarik untuk meneliti faktor terpenting dalam membangun unique selling proposition untuk menjangkau konsumen kelas menengah indonesia.

\section{Rumusan Masalah}

Merujuk dari latar belakang masalah yang telah dijabarkan, maka akan dilakukan serangkaian penelitian untuk menjawab rumusan masalah yang ada dalam penelitian ini yaitu: Apa faktor terpenting dalam membangun unique selling preposition untuk menjangkau konsumen kelas menengah indonesia?

\section{Metode Penelitian}

Penelitian ini menggunakan desain metode penelitian triangulasi yang sering digunakan dalam penelitian sains sosial yang memfasilitasi validasi data melalui verifikasi silang dari dua sumber atau lebih. Secara khusus, ini mengacu pada aplikasi dan kombinasi beberapa metode penelitian dalam studi fenomena yang sama (Bogdan \& Biklen, 2006).

Dengan menggunakan metode penelitian triangulasi kita dapat memeriksa data dari berbagai sumber untuk keteraturan (O'Donoghue \& Punch, 2003) dan akan memiliki gambaran situasi yang lebih rinci dan seimbang (Altrichter, 2008; McCutcheon \& Meredith, 1993). Ada empat jenis dasar triangulasi yang diciptakan oleh Denzin pada tahun 1978:

Metodologi Triangulasi: melibatkan penggunaan lebih dari satu metode untuk mengumpulkan data, seperti wawancara, observasi, kuesioner, dan dokumen.

Metodologi triangulasi digunakan untuk membandingkan data dari tinjauan Literatur, Wawancara. Tinjauan literatur akan membandingkan disain, dan teori Branding, untuk keluar dengan koneksi teori, Wawancara akan menggunakan data triangulasi untuk mengumpulkan informasi dengan mewawancarai praktisi dan akademisi Branding. 
1. Alvin Raditya, founder dari Visual Cast, sebuah perusahaan branding yang berdiri sejak 2004, selain itu beliau juga berprofesi sebagai dosen desain komunikasi visual di beberapa universitas di Surabaya.

2. Amelia Sidik, founder Lia Sidik \& Associate, sebuah perusahaan branding yang berdiri sejak tahun 2006, seorang $\mathrm{PhD}$ di bidang Creative industry and art practice, yang juga mengajar di beberapa universitas di Indonesia.

3. Jacky Cahyadi, co-founder actionframe animation studio yang berdiri sejak 2005, sekaligus dosen desain komunikasi visual di beberapa kampus di Surabaya.

\section{Pembahasan}

\section{Unique Selling Proposition}

Dengan berkembangnya pasar dan meningkatnya perdagangan maka para pebisnis harus memikirkan cara agar bisa memenangkan persaingan. Salah satu cara adalah dengan Unique Selling Proposition. Unique Selling Proposition ini dikembangkan oleh Rosser Reeves, pendekatan ini berorientasi pada keunggulan atau kelebihan produk yang tidak dimiliki oleh produk pesaing. Kelebihan tersebut juga merupakan sesuatu yang dicari atau dijadikan alasan bagi konsumen menggunakan suatu produk.

Unique Selling Proposition merupakan salah satu strategi marketing dan sekaligus kunci untuk membedakan produk dari pesaing. Unique Selling Proposition adalah perpaduan dari keunikan fitur, keuntungan dan nilai yang dapat diberikan dan tidak diberikan oleh pesaing lainnya. Oleh sebab itu, maka Unique Selling Proposition sangatlah penting untuk dilakukan di era kompetitif seperti sekarang ini.

Untuk menentukan Unique Selling Proposition pada suatu produk tertentu bukanlah sesuatu yang mudah, karena sekarang telah banyak berdiri perusahaan-perusahaan yang bermain di bisnis yang sejenis. Jika produk tidak memiliki keunikan untuk dipasarkan, itu artinya sama saja menjual produk yang sama denganpesaing kita (Bob Janet 2008:1).

Menggunakan Unique Selling Proposition akan meningkatkan posisi dan pemasaran perusahaan dan produk dengan melakukan 3 hal ini:

- Unique: Hal ini membuat produk berbeda dengan pesaing lainnya

- Selling: Mengajak pelanggan untuk membeli produk yang ditawarkan, menukar uang untuk produk atau jasa
- Proposition: Penawaran atau usulan yang disarankan untuk diterima.

Dikutip dalam buku Tellis dan Ambler (2007 : 3536) mendefinisikan konsep Unique Selling Proposition mengharuskan perusahaan untuk membuat proposisi untuk pelanggan agar membeli produk dan mendapatkan manfaat. Unique Selling Proposition mendasari gagasan dari differentiation fungsional, daya tarik massa dan iklan berulangulang, yang difaktori oleh ketatnya persaingan dan peningkatan distribusi akibat dari lingkungan ekonomi. Salah satu bentuk unique selling proposition adalah branding.

\section{Branding}

Disadari atau tidak, brand telah menjadi bagian dari kehidupan setiap manusia. Tetapi tidak semua orang mengetahui brand yang kita miliki. Sangat penting membangun brand yang kuat dan terus meningkat, karena perusahaan menghadapi persaingan yang ketat, serta kondisi pasar yang stagnan dan meningkatnya persaingan global, (Low and Lamb, 2000; Narisetti, 1998)

Model positioning yang didasarkan pada persepsi konsumen telah menjadi alat yang sangat berharga bagi pemasar karena kemampuan diagnostik mereka serta kemampuan mereka untuk secara visual menggambarkan pasar yang kompetitif (Desarbo et al., 2002).

Positioning - Clarification: Langkah ini bertujuan untuk mengetahui persepsi masyarakat atau target market dituju terhadap sebuah brand. Langkah ini perlu diklarifikasi secara berkala karena persepsi manusia bisa berubah dengan berjalannya waktu. Jika persepsi di mata masyarakat negatif, maka perlu ada kampanye untuk mengedukasi ulang masyarakat agar persepsi bisa berubah. Namun bila persepsi sudah positif, maka perlu ada apresiasi atau tanda terima kasih atau berbagai hal untuk mempertahankan persepsi masyarakat yang sudah positif.

Professor Kevin Lane Keller menciptakan sebuah terknik marketing yaitu Brand Ladder.

"Brand Laddering involves progression from attributes to benefits to more abstract values or motivations. Laddering involves repeatedly asking what the implication of an attribute or benefit is for the customer."

Brand Laddering berguna untuk merumuskan Positioning sebuah brand. Sebenarnya Brand Ladder terdiri atas 3 tingkatan, akan tetapi beberapa ahli marketing menambahkan tingkat 
ke-4, yaitu Personal Values yang menjelaskan motivasi pribadi yang terdalam mengenai prinsip dan nilai hidup seseorang:

- Nilai Pribadi: Tujuan pribadi yang stabil dan abadi. Milik, harga diri, keamanan, kemandirian.

- Manfaat Psikososial: Pengalaman emosional berasal dari memiliki atau menggunakan atau mengalami produk atau layanan. Berkaitan dengan diri sendiri.

- Manfaat Fungsional: Pengalaman fisik berasal dari konsumsi. Berkaitan dengan produk atau layanan itu sendiri.

- (Teknis) Atribut: Hal-hal yang dapat kita mengusahakannya, atau karakteristik langsung dari susunan fisik produk. "Warna" adalah hasil dari "cat", namun bisa dianggap sebagai atribut. Produk / kualitas layanan yang dirasakan sering menjadi dasar perbedaan

Attributes dan Functional Benefit memiliki sifat yang melekat pada produk atau jasa, sedangkan dua tingkatan ke atas lebih mengarah pada manfaat bagi pengguna. Saat sebuah segmen konsumen telah ditetapkan, maka Brand Ladder dapat memetakan rangkaian aspek-aspek menjadi sebuah pesan yang spesifik untuk tipe konsumen tersebut.

Brand Driver: Konsep strategi branding yang digunakan oleh Landor menggunakan istilah Brand Driver atau Brand Essence, yang di dalamnya terkandung Brand Verbal, Brand Attributes, dan Brand Visual.

Hal ini sesuai dengan hasil wawancara:

1. Alvin: brand position identification, mengidentifikasikan positioning apa yang ingin dimiliki oleh brand, positioning yang dituju ini haruslah sesuai dengan karakteristik dan kebutuhan dari calon target konsumen. Dengan begitu positioning yang dibuat bisa dengan mudah diterima oleh konsumen karena dianggap mengerti kebutuhan mereka dan mampu menyelesaikan permasalahan yang mereka hadapi.

2. Jacky: brand promise. Jacky menjelaskan, dengan keunikan nilai yang ditemukan tersebut dan segmen yang dituju, brand harus merumuskan brand promise dan positioning (brand positioning). Tahap ini akan dirumuskan tentang bagaimana brand ingin dikenal dan dibedakan dengan brand lain oleh konsumennya. Untuk membuat nilai tersebut dapat melekat di benak konsumen, maka brand harus berkomitmen untuk menjaga supaya nilai yang dia tawarkan tersebut bisa selalu konsisten dan memiliki performa yang baik (brand commitment).
3. Lia: menciptakan sebuah pesan komunikatif yang dibutuhkan oleh target konsumen. Pesan tersebut disusun dengan cara mentriangulasi data internal dan eksternal perusahaan untuk memperoleh kesamaan dan perbedaan antara brand dengan pesaingnya (point of parities dan differentiate). Dari situ akan diketahui apa yang telah dilakukan oleh competitor, strategi mana yang berhasil dan mana yang gagal. Kemudian hasilnya digunakan untuk menciptakan brand character sehingga brand memiliki karakter, perbedaan dan nilai jual (unique selling preposition) yang komunikatif sesuai dengan kebutuhan konsumen.

4. GGB: Brand Positioning - tahap yang berisi tentang bagaimana dapat memulai membangun identity, membuat image, dan menggabungkannya menjadi integrity dengan memahami keinginan dan kebutuhan seluruh stakeholders secara berkelanjutan. Kunci dari marketing strategy adalah membedakan startup dengan produk atau layanan lainnya di benak pengguna.

\section{Konsumen Kelas Menengah Indonesia}

Berdasarkan data dari World Bank, pada 2003 jumlah kelas menengah di Indonesia tercatat 81juta orang. Angka tersebut meningkat, hingga pada 2010 jumlahnya mencapai 131 juta orang. Diprediksi setiap tahun akan jumlah kelas menengah akan bertambah 7 juta orang Indonesia. Sementara, menurut Boston Consulting Group (BCG) pada tahun 2020 akan ada sekitar 141 juta populasi kelas menengah di Indonesia. Jumlah tersebut melebihi total populasi negara-negara di ASEAN lain, termasuk Malaysia, Thailand dan Filipina.

Makna kelas menengah yang dianggap sebagai kelas konsumen baru perlu mendapat pengertian yang jelas. Hal ini terkait dengan arti "baru" yang dilekatkan dalam perilaku konsumtif kelas menengah tersebut. Pengertian baru tersebut merujuk pada pertumbuhan ekonomi yang tinggi dan stabil sehingga terjadi penguatan pembangunan ekonomi negara. Kenaikan jumlah pendapatan dengan jumlah konsumsi tersebut mengindikasikan adanya pola konsumsi baru. Dalam mencermati pertumbuhan konsumsi, analisis kontemporer melihat hal ini karena adanya lonjakan harga yang menstimulus para kalangan menengah untuk menghabiskan uangnya.

Menurut Yuswohady (2014) dalam Consumer 3000 mengatakankan bahwa ada korelasi antara kenaikan pendapatan negara dengan pendapatan masyarakat. Secara khusus, terjadi perubahan 
orientasi dalam melakukan konsumsi karena pemenuhan kebutuhan dasar tidaklah menempati posisi puncak untuk dipenuhi ketika pendapatan negara berada dalam ambang batas psikologi mencapai USD 3000 per tahun.

Pergeseran dalam konsumsi tersebut sebenarnya berkorelasi terhadap pemenuhan gaya hidup dan simbol. Munculnya era budaya konsumen yang semakin berkembang seringkali dilihat dari tingkat faktor sosial ekonomi masyarakat yang memiliki daya beli cukup tinggi. Selain dari sisi peningkatan pendapatan, kebangkitan budaya konsumen dalam berbelanja sangatlah erat dilihat dari kacamata sosiologis yang menempatkan definisi pembentukan identitas gaya hidup sebagai bagian untuk membedakan seseorang dengan orang lain. Proses ini terjadi pada sebuah tahapan perkembangan unsur-unsur masyarakat yang ada di perkotaan atau lebih dikenal dengan masyaraka urban.

Dalam kajian Mckenzie tentang perilaku berkonsumsi kelas menengah Indonesia, menunjukkan bahwa kelas menengah Indonesia lebih banyak menjadi price hunter dalam membeli suatu barang atau jasa. Hasil penelitian markplus pada tahun 2012 tentang perilaku konsumsi kelas menengah, menemukan sebuah kesimpulan yang cukup menarik. Meskipun sebagian besar kelas menengah termasuk price hunter namun bukan berarti mereka tidak menyukai barang branded, justru dua hal ini berjalan bersamaan. Dalam bahasa yang sederhana meskipun barang atau jasa yang dikonsumsi berharga murah namun bukan berarti "murahan".

\section{Simpulan}

Dengan meningkatnya pertumbuhan ekonomi di Indonesia serta untuk memenuhi kebutuhan belanja kelas menengah merupakan peluang bisnis bagi para pengusaha di Indonesia. Untuk membangun bisnis yang sukses dan bisa menjangkau kelas menengah Indonesia diperlukan Unique Selling Proposition.

Terinspirasi dari studi literatur yang ada dan juga dengan wawancara kepada enam narasumber dalam membangun Unique Selling Proposition ada empat hal yang perlu dilakukan yaitu dengan langkah awal membuat visualisasi brand yang akan dibentuk ke depannya. Berikut adalah penjelasan tentang empat hal tersebut dalam langkah keenam brand driver ini.

- Menjelaskan definisi brand verbal. Brand verbal adalah deskripsi singkat yang bertujuan untuk memberikan makna dan konteks pada sebuah brand. Brand Verbal menjelaskan Unique Selling Proposition (USP) atau yang juga dikenal dengan Value Proposition dari sebuah produk, memberikan sebuah definisi tentang suatu brand dan bagaimana brand tersebut menawarkan sebuah janji kepada konsumennya, dan bagaimana brand tersebut berbeda dari kompetitornya.

- Menyebutkan brand attributes/brand mantra/ brand values.Brand Attributes adalah beberapa kata kunci (keywords) yang diambil dari Brand Verbal/ USP. Kata-kata kunci tersebut dapat dikembangkan untuk menjadi sebuah Brandline atau Tagline. Brandline adalah sebuah permainan kata yang dapat menjelaskan jenis atau kategori produk. Sedangkan Tagline adalah permainan kata yang bertujuan untuk menyampaikan sebuah pesan marketing. Oleh sebab itu Tagline dapat berubah seiring dengan waktu dan tahapan komunikasi, sedangkan Brandline lebih bersifat permanen. Brand Values disebut juga sebagai Brand Mantra atau Brand Values.

- Membuat mood board yang menggambarkan visual brand yang akan dibuat. Brand Visual adalah kumpulan visual yang dapat merepresentasikan kata-kata kunci Brand Attributes dengan lebih spesifik. Brand Visual berfungsi seperti Mood Board yang dapat menjadi inspirasi dalam mendesain atau menemukan kombinasi warna yang sesuai untuk merepresentasikan suatu kata kunci.

- Merumuskah tagline/brandline dan brand promise yang diambil dari brand verbal dan atributnya.

- Tujuan dari langkah ketujuh atau brand driver adalah untuk membuat karakteristik dari sebuah brand dari informasi-informasi yang sudah didapatkan dalam keenam langkah sebelumnya. Tentu saja langkah ini sudah pasti ada dalam setiap studi literatur yang ada maupun wawancara dengan narasumber.

Dalam Design Thinking, langkah ini termasuk dalam ideate yang merupakan langkah awal dan memvisualisasikan sebuah brand. Hal ini juga termasuk dalam langkah composing message dalam Delphie Process. Semua narasumber pun juga mengatakan hal yang sama dalam langkah ini.

\section{Daftar Pustaka}

Aaker, D.A. (1996), "Measuring brand equity across products and markets", California Management Review, Vol. 38, pp. 102-20. 
Al Ries and Jack Trout, (1993), The 22 Immutable Laws of Marketing, New York: Harper Business , 19.

Alba, J.W. and Hutchinson, J.W. (1987), "Dimensions of consumer expertise", Journal of Consumer Research, Vol. 13, pp. 411-54.

Altrichter, H., Feldman, A., Posch, P. \& Somekh, B. (2008). Teachers investigate their work; An introduction to action research across the professions. Routledge. p. 147. (2nd edition).

Amit K. Ghosh Goutam Chakraborty, (2004), "Using positioning models to measure and manage brand uncertainty", Journal of Product \& Brand Management, Vol. 13 Iss 5 pp. 294 - 302

Banerjee, Abhijit dan Esther Dufflo, (2008), What is Midlle Class About Middle Classes Around The World?. Working Paper: Massachusetts Institute of Technology Department of Economics.

Bettman, J.R. (1979), An Information Processing Theory of Consumer Choice, Addison-Wesley, Reading, MA.

Bettman, J.R. and Park, C.W. (1980), "Effects of prior knowledge and experience and phase of the choice process on consumer decision processes: a protocol analysis", Journal of Consumer Research, Vol. 7, pp. 234-48.

Bogdan, R. C. \& Biklen, S. K. (2006). Qualitative research in education: An introduction to theory and methods. Boston, Allyn \& Bacon.

Bristow, D.N., Schneider, K.C. and Schuler, D.K. (2002), "The brand dependence scale: measuring consumers' use of brand name to differentiate among product alternatives", Journal of Product \& Brand Management, Vol. 11, pp. 343-56.

Brucks, M. (1985), "The effects of product class knowledge on information search behavior", Journal of Consumer Research, Vol. 10, pp. 114.

Cahyadi. Jacky (2017, May 19). Branding process (Personal Interview). Importand steps of branding process.

Denzin, N. (2006). Sociological Methods: A Sourcebook. Chicago, Aldine Transaction.

Desarbo, W.S., Kim, J., Choi, S.C. and Spaulding, M. (2002), "A gravity-based multidimensional scaling model for deriving spatial structures underlying consumer preferences/choice", Journal of Consumer Research, Vol. 29, pp. 116.

Freischlad, N. (2017, August). Indonesians are founding fewer startups now than five years ago. https://www.techinasia.com/indonesiawhere-are-the-startups

Johnson, E.J. and Russo, J.E. (1984), "Product familiarity and learning new information",
Journal of Consumer Research, Vol. 11, pp. 542-50.

Keller, K.L. (1998), Strategic Brand Management: Building, Measuring, and Managing Brand Equity, Prentice Hall, Upper Saddle River, NJ.

Low, G.S. and Lamb, C.W. (2000), "The measurement and dimensionality of brand association", Journal of Product and Brand Management, Vol. 9, pp. 350-68.

McCutcheon, D.M., Meredith, J. (1993). Conducting case study research in operations management. Journal Operattion Management, 11 (3), pp. $239-256$.

McKinsey Global Institute. (2012). The Archipelago Economy: Unleashing Indonesia's Potential. McKinsey \& Company.

McKinsey Global Institute. (2012). The New Indonesian Consumer. McKinsey \& Company.

Moendanton, A. (2015, April). Investor's guide to Indonesia: The most promising startup sector. http://indonesiaexpat.biz/business-property/ investors-guide-to-indonesia-the-most-promising-startup-sectors/)

Mooy, S.C. and Robben, H. (2002), "Managing consumers' product evaluation through direct product experience", Journal of Product \& Brand Management, Vol. 11, pp. 432-46.

Narisetti, R. (1998), "New and improved", Wall Street Journal, p. R33.

O'Donoghue, T., Punch K. (2003). Qualitative Educational Research in Action: Doing and Reflecting. Routledge. p.78

Raditya. Alvin (2017, May 118). Branding process (Personal Interview). Importand steps of branding process.

Rao, A.R. and Monroe, K.B. (1988), "The moderating effects of prior knowledge on cue utilization in product evaluations", Journal of Consumer Research, Vol. 15, pp. 253-64.

Rothbauer, Paulette. (2008) "Triangulation." In Given, Lisa (Ed.), "The SAGE Encyclopedia of Qualitative Research Methods." Sage Publications. pp. 892-894.

Sidik. Amelia (2017, May 15). Branding process (Personal Interview). Importand steps of branding process.

Sujan, M. (1985), "Consumer knowledge: effects on evaluation strategies mediating consumer judgments", Journal of Consumer Research, Vol. 12, pp. 31-46.

Suyanto. M. Strategi Perancangan Iklan Televisi Perusahaan Top Dunia. Andi.Yogyakarta. (2005). Hlm 79

Tri Wahyuningrum, Unique Selling Proposition dalam desain kaos. Skripsi Programstudi ilmu komunikasi fak. Ilmu sosial dan ilmu 
politik Univ Sebelas Maret. Surakarta 2010. hal 31.

Widiatmanti, H. (2015, April). Penghasilan kelas menengah naik $=$ potensi pajak?. http://www. bppk.kemenkeu.go.id/publikasi/artikel/167artikel-pajak/21014-penghasilan-kelas-menengah-naik-potensi-pajak.
Yuswohady. (2013). Consumer 3000:Revolusi Konsumen Kelas Menengah Indonesia. Jakarta: Gramedia.

Zeithaml, V.L. (1988), "Consumer perceptions of price, quality, and value: a means-end model and synthesis of evidence", Journal of Marketing, Vol. 52, pp. 2-22. 